\title{
Research and Analysis of Automated Special Machine for Fastening of U-Frame and Screw
}

\author{
Vincent Balu
}

\begin{abstract}
This paper introduces the Design, Modeling and Simulation of a special tool that attaches a screw to attach the screw to a bimetal of MCB (Miniature Circuit Breaker). Problems found in the current process include complex shape and screw size and full connection operation is an intensive manual operation which makes handling difficult for the operator and also the size of the M2 screw and is headless with a cross section. In partnership with the SPM operator works as a tool to increase productivity by reducing operator fat. The system is a testament to automated material handling system, serial transfer, trap detection, attachment, automatic ejecting system, actuator system, sensors and control capabilities etc. Small screw handling and bike prospect are the major challenges in the special development of a purpose screw attachment system. System Modeling \& Simulation analysis is done and the results are encouraging.
\end{abstract}

Keywords- Modelling, MCB, Simulation, Ejecting system, SPM, Fastening tool.

\section{INTRODUCTION}

Today the improvement of technologies made it possible to integrate business automation systems into almost every area of manufacturing. Industrial automation of production processes increases labor efficiency and allows cutting net cost and improving product quality [1], [2].

In addition, it extends equipment service/facility life, protects consumables \& raw materials, \& progresses overall production safety. Computerization or automatic control is the employment of a variety of control methods for operating apparatus/tools such as appliances, factory processes, boilers \& heat treatment ovens, switch on telephone/mobile networks, management \& stability of ships, aircraft \& additional applications with very little human intervention [3]-[5].

More or less procedures have been entirely automated. The greatest advantage of automation/robotics is that the aforementioned procedure saves labor, yet it is correspondingly employed to protect energy \& materials \& to increase quality, precision \& accuracy. Automation/robotics has been accomplished in various ways involving mechanical, irrigation, pine, electrical, electrical and computer equipment, usually combined [6], [7].

Complex arrangements, like as modern place of work, aircraft \& ships characteristically employed these mutual techniques.

The main profits of automation are:

$>$ Increased mobility or productivity.

$>$ Better quality or more quality.

Revised Manuscript Received on August 05, 2019.

Vincent Balu, Department of Mechanical Engineering, Sanskriti University, Uttar Pradesh, India. (E-mail: sanpubip@gmail.com)
$>$ Improved strength (consistency), processes or output [8], [9].

K FELDMANN, M STEBER - An integrated computer system has been technologically advanced, which helps to design and control the screw attachment process. The idea was systematically tested in a collector cell by a gantry robot, which handles bolt spindles. The enhanced program can control multiple voltage processes simultaneously. In addition, relevant process data can be recorded and stored. If the process fails the additional monitoring system assists the supervisor to resolve the problems [10].

ZAHARI TAHA, \& SITI ZAWIAH MD DAWAL, \& SIOW-WEE CHANG - An automatic screw attachment process for small screws has been efficaciously established. Three different sensors were used to quantify the force curve, torque curve and screwdriver rotational speed. A programmable horizontal servo slide was taught to perform the binding operation. Experiment design was used to identify the important factors that could stimulus the final torqueing process. Additionally to the size of screw material and work piece, the screw head geometry, rotor driver speed, and servo sliding speed have a significant influence on the final torqueing process [11], [12]

ZHIQIANG GAO \& THOMAS A. TRAUTZSCH - A smart control tactic has been developed for automatic screw attachment. In automatic assembly processes, coolant stations are normally found for different types / sizes of screw attachment. Glitches found in the conventional procedures comprise cross threading, \& screw jamming, \& slip \& the need to relate precise torque. The smart controller established here monitors the integrated processor of an electric driver mounted on a robotic locating system to attach screws. The novel scheme continuously controls the movements \& drive levels to keep away from procedure induced failures, precise torque you want to achieve $\&$ to identify bad portions at the early stages of assembly [13].

\section{INTRODUCTION TO SPECIAL PURPOSE MACHINES [14]-[17]}

Increase in output rate but human speed is almost constant. To enable an increase in productivity, automation/robotics is a key capability. One such problem in the switching gear industry, of attaching a calibration screw in a bimetal is an intensive manual operation. In addition to the increased demand, the operator is concerned with the limitation of screw size and shape.

To overcome this challenge an automated solution is required. A special purpose tool for attaching a screw has

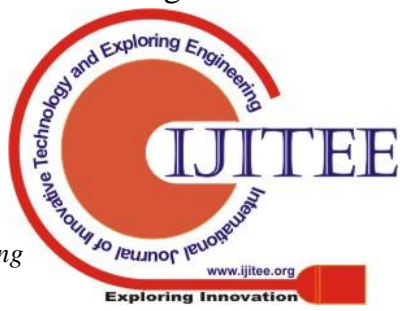


been advanced. In partnership with the operator the SPM acts as a tool to enhance by reducing the operator's obesity.

The system verifies automatic material handling, serial movement, trap detection, attachment system, sensors and control capabilities.

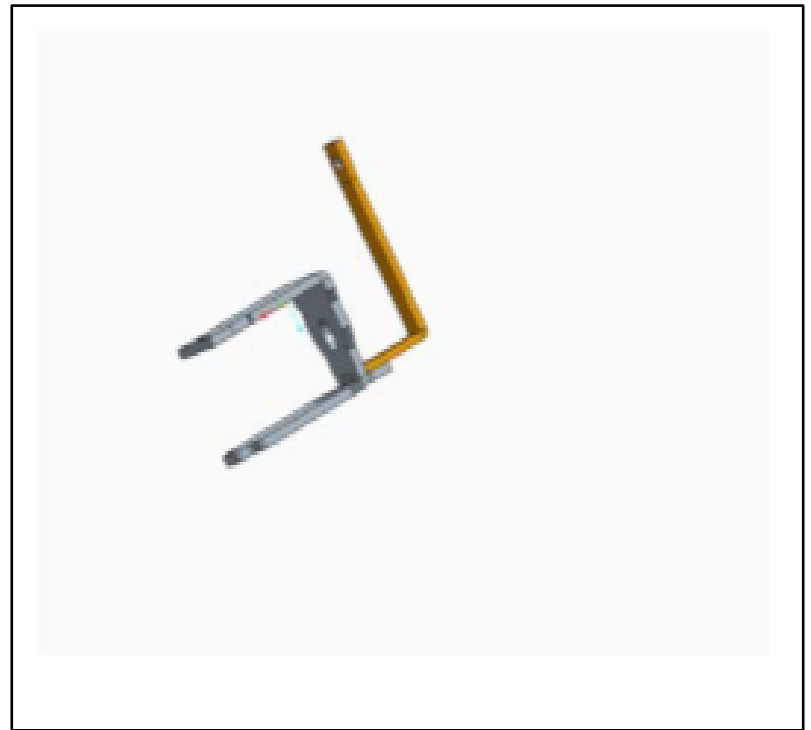

Figure 1. U-Frame Bimetal Assembly

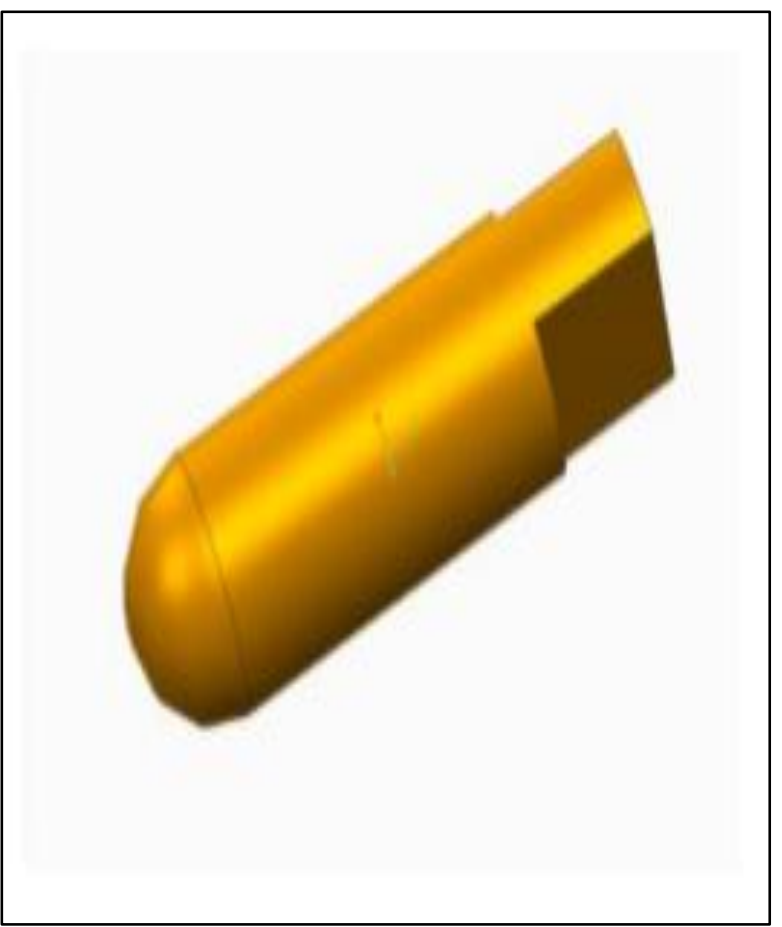

Figure 2. Screw used in the experiment

The special tool includes -

$>$ Buffer system

$>\quad$ Serial bowl feeder

$>\quad$ Gripper clamping tool

$>\quad$ Piston cylinder arrangement via Torsional fountain

$>$ Discharge range

$>\quad$ Motor stepper

$>\quad$ Different kinds of cylinders

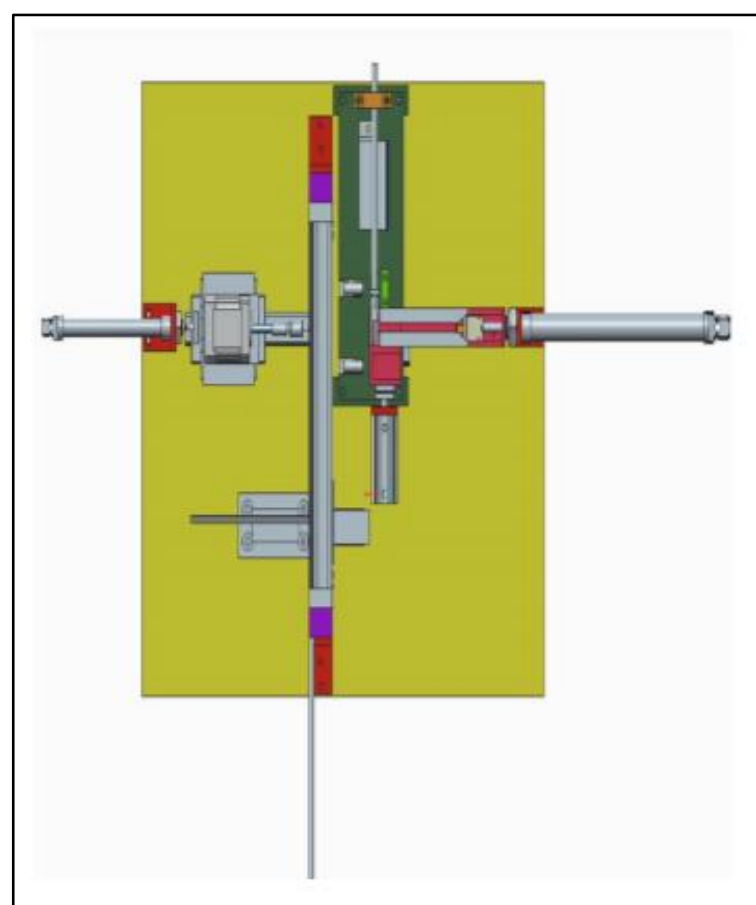

Figure 3. Front View of SPM



Figure 4. Top View of SPM

\section{Flowchart for Operation of SPM}

The flowchart for the operation of the SPM is described below as illustrated in

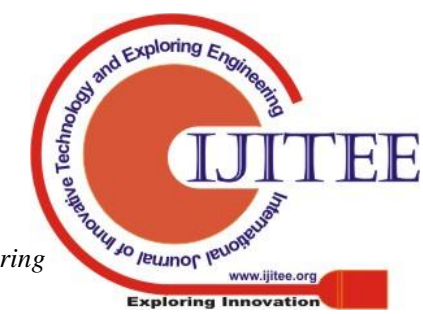




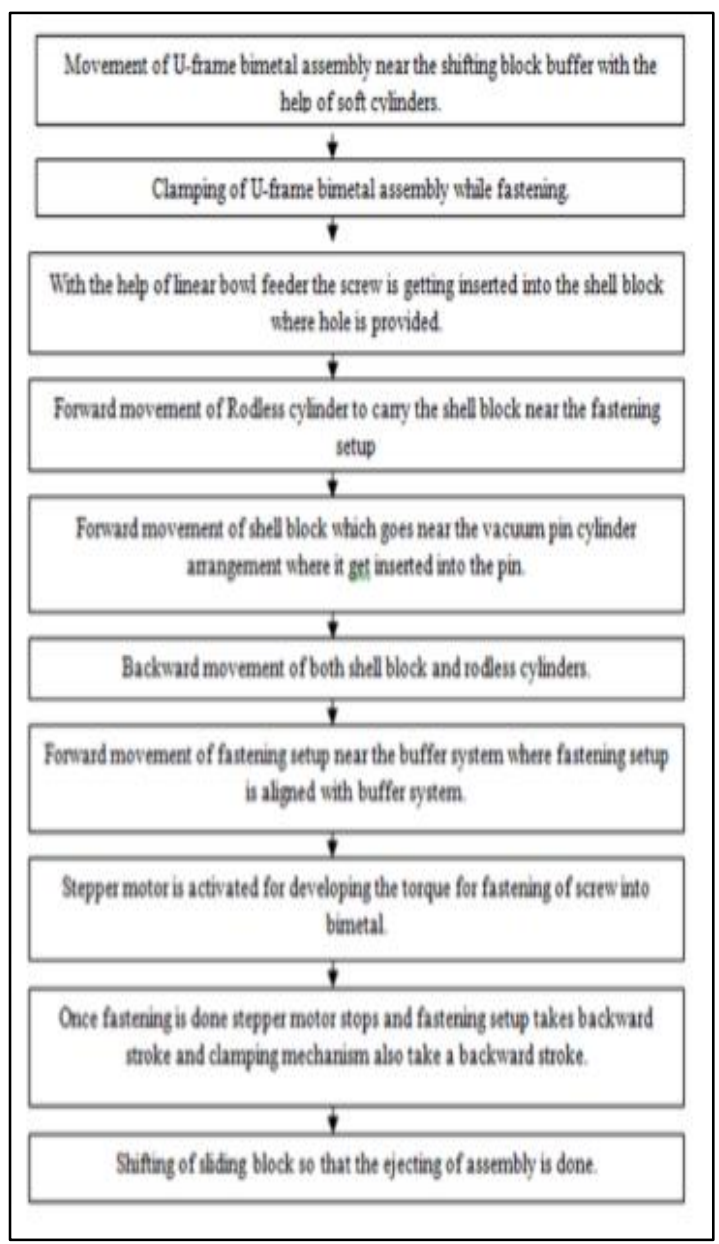

Figure 5. Flowchart for operations of SPM

\section{RESULTS}

\section{Theoretical Calculation-}

The requirement of torque for the fastening of the screw into U-frame is calculate by this procedure.

Torque required for metric screw thread M2, T $=0.17 \mathrm{Nm}$ and this the exact amount of torque required for the aforementioned procedure.

$\mathrm{RPM}=1600$ for the .025 pitch, therefore the RPM = 4000.

Axial force required as a consequence of the cylinder acting on screw. Axial force, $\mathrm{F}=39.27 \mathrm{~N}$.

The axial force acting on the U-frame subassembly near the fastening area is $\mathrm{F}=10 \mathrm{~N}$.

Creo Simulate FEA is a structural, \& thermal \& vibration analysis explanation with a widespread set of capabilities that permits you to study \& authorize the presentation of your 3D virtual prototype before creating the first part. From academic calculations, $\mathrm{F}=39.2695 \mathrm{~N}, \mathrm{~T}=0.18 \mathrm{Nm}$ which is directed to the screw and $\mathrm{F}=10 \mathrm{~N}$ is used to the U-frame assembly, the software is given as input \& the equivalent outcomes are achieved.

\section{Steps Made in Pressure Analysis}

$>\quad$ An illustrated model is opened in Creo Simulate.

$>$ Provide the Material Properties and Specify the Material to Study.

Replace inputs like as force, Torque, and Release limitation to the component. $>\quad$ Auto Gem, create a p-mesh for modeling geometric elements.

$>\quad$ In Monitoring and studying

- Run the analysis.

- If analysis is completed, refer to results of completed element analysis.

If the results obtained are below the allowed level, it is otherwise safe to return to Step 2.

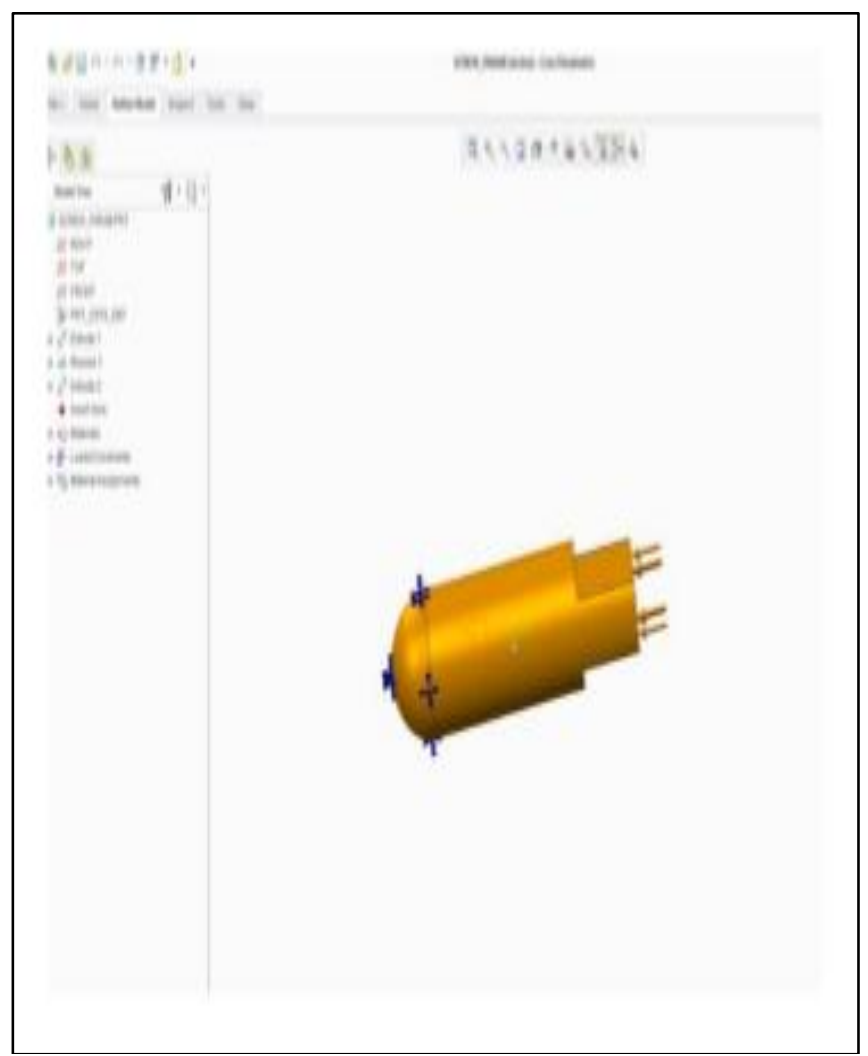

Figure 6. Application of Force and Torque on Screw

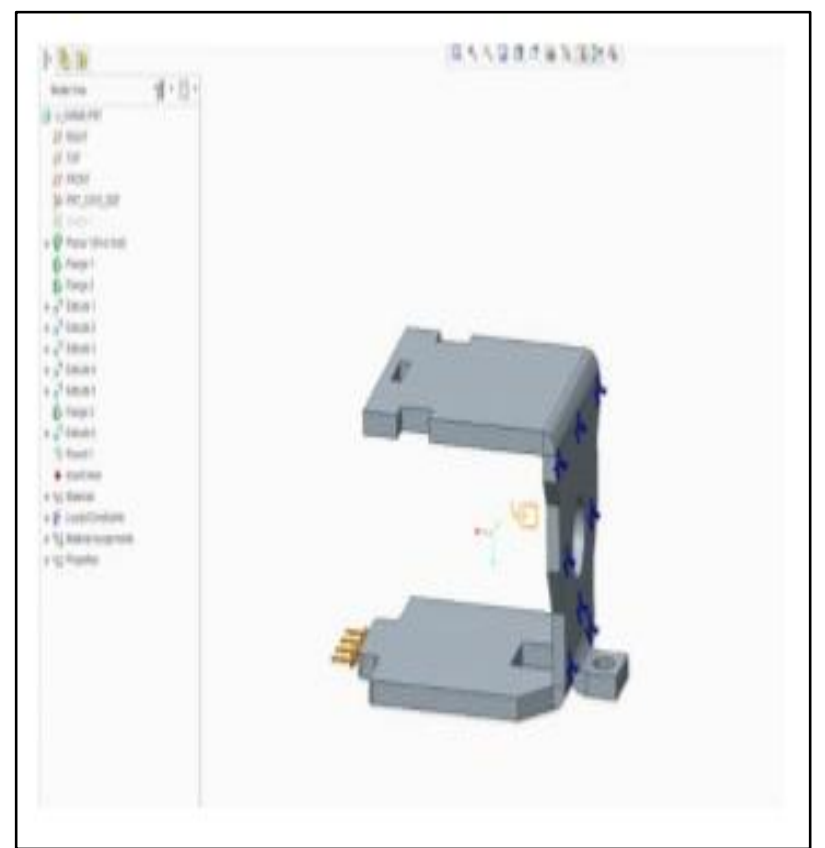

Figure 7. Application of Force on U frame Assembly

Published By: Blue Eyes Intelligence Engineering 


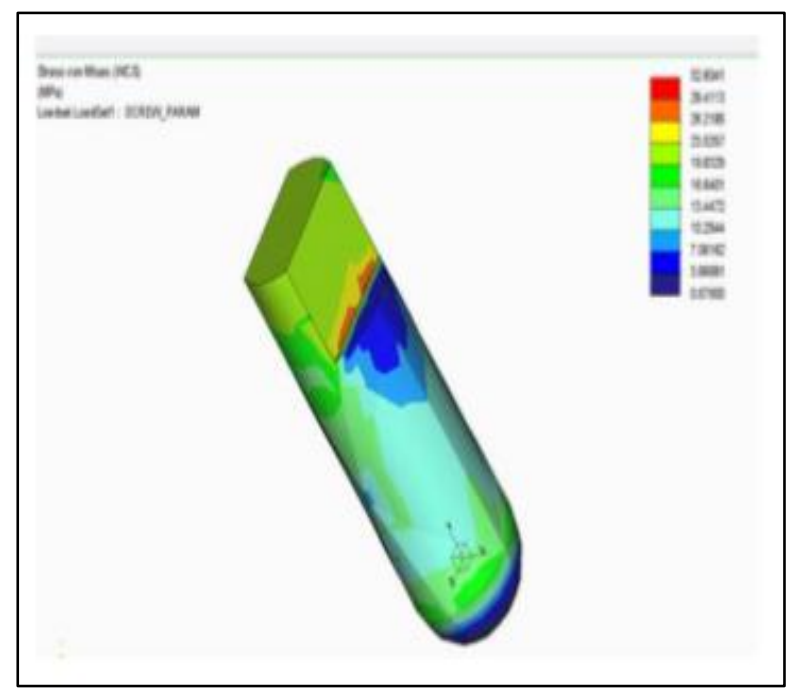

Figure 8. Stress Analysis of Screw

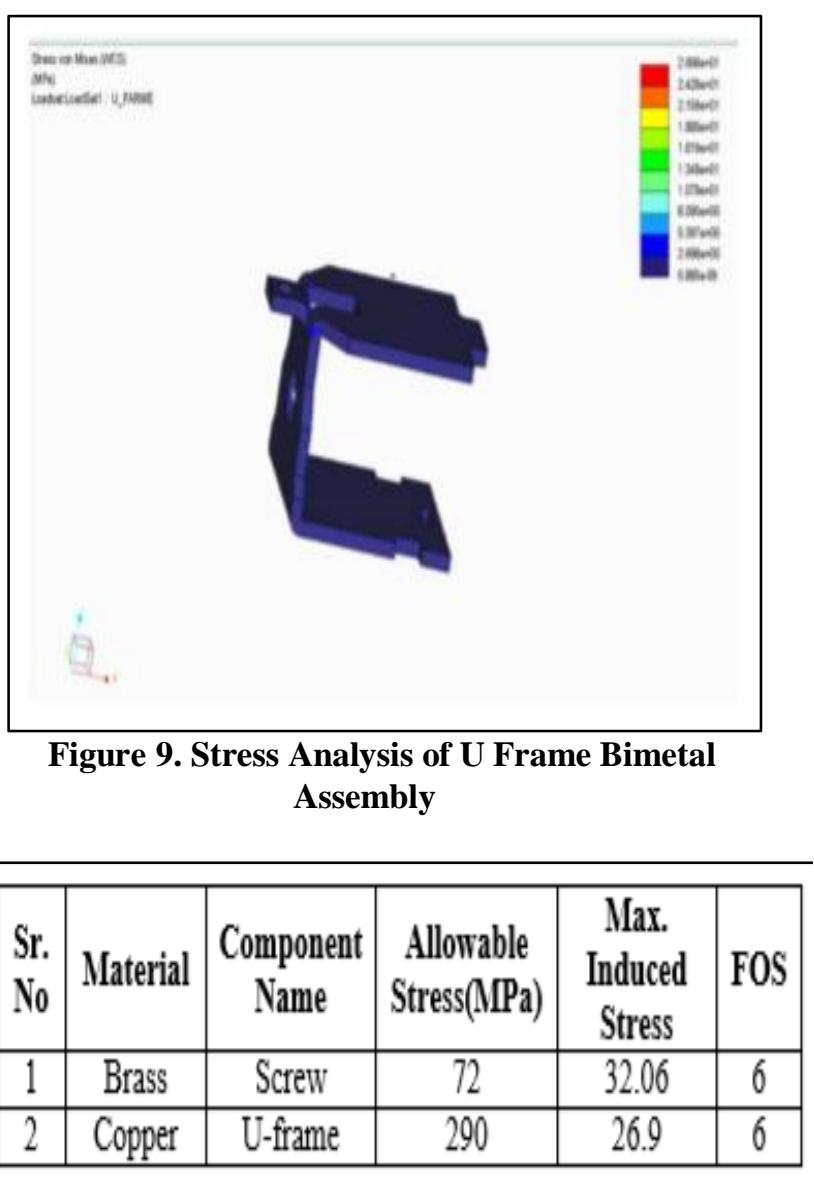

Figure 10. Results of the Simulation

From the above results it is clear that both screw and Uframe assembly are both safe, given that induced pressure is a lesser amount of the allowable pressure.

\section{CONCLUSION}

Because of its boundaries; for attaching a screw by hand into a bimetal that spends more time recovering by developing the special purpose machine. In conglomerate through the operator, the SPM works as a tool to increase efficiency by dropping fatigue chances \& human involvement. The improvement in a special purpose automatic tool for attaching a screw into a U-frame bimetal assembly with the intention of a hominoid machinist can be removed $\&$ a screw can be attached in a faster $\&$ simpler manner compared to the process of which. Stress Analysis of moving parts is done on various load settings and its results are safe.

\section{REFERENCES}

1. ScienceDirect (Online service), Engineering applications of artificial intelligence. Pineridge Periodicals, 1988.

2. ACSE - The University of Sheffield.

3. Zhongguo ke xue yuan. Zidonghua Yanjiuyuan., International journal of automation and computing. [Editorial Board of International Journal of Automation and Computing].

4. C. T. Kilian, Modern control technology: components and systems. Delmar/Thomson Learning, 2006.

5. A. Zankl and Siemens Aktiengesellschaft., Milestones in automation: from the transistor to the digital factory. Publicis Corporate Publishing, 2006.

6. Control Engineering | What is Engineering." [Online]. Available: http://whatisengineering.com/topic/what-iscontrol-engineering/. [Accessed: 06-Aug-2019].

7. Z. M. Wang and L. Y. T. Lang, "Bi is a Research Officer of Integrated Manufacturing Technologies Institute at National Research Council of Canada. He received a $\mathrm{PhD}$ degree in Mechatronic Control and Automation from Harbin Institute of Technology," 2007.

8. K. Dharmaraj, "AUTOMATED FREEFORM ASSEMBLY OF THREADED FASTENERS," 2015.

9. [9] K. Dharmara, R. P. Monfared, P. S. Ogun, and M. R. Jackson, "Robotic assembly of threaded fasteners in a non-structured environment," Int. J. Adv. Manuf. Technol., vol. 98, no. 5-8, pp. 2093-2107, Sep. 2018.

10. K. Feldmann and M. Steber, "Screw Fastening in Flexible Automated Assembly with Computer-Integrated Process Control," CIRP Ann., vol. 41, no. 1, pp. 41-44, Jan. 1992.

11. "Most Advanced Robotics Simulation Software Overview." [Online]. Available: https://www.smashingrobotics.com/most-advanced-andused-robotics-simulation-software/. [Accessed: 06-Aug2019]

12. H. J. Yap, Z. Taha, S. Z. Md Dawal, and S.-W. Chang, "Virtual Reality Based Support System for Layou Planning and Programming of an Industrial Robotic Work Cell," PLoS One, vol. 9, no. 10, p. e109692, Oct 2014.

13. Z. Gao, T. A. Trautzsch, and J. G. Dawson, "EngagedScholarship@CSU A Stable Self-Tuning Fuzzy Logic Control System for Industrial Temperature Regulation," 2002.

14. Zhiqiang Gao, T. A. Trautzsch, and J. G. Dawson, "A stable self-tuning fuzzy logic control system for industrial temperature regulation," in Conference Record of the 2000 IEEE Industry Applications Conference. Thirty-Fifth IAS Annual Meeting and World Conference on Industrial Applications of Electrical Energy (Cat No.00CH37129), vol. 2, pp. 1232-1240.

15. Journal of communication and computer. David Publ, 2010.

16. Leonardo journal of sciences : LJS. 2002

17. R. Lasri, I. Rojas, and H. Pomares, "Fuzzy Logic Controllers Improves Human Daily Life. The StateOfThe Art 'Best Accuracy and More Flexibility,"' Int. J. Comput. Appl., vol. 23, no. 9, pp. 1-9, Jun. 2011 